\section{NOVEL C-3 CYCLIC ETHER CEPHALOSPORINS AND THEIR ORALLY ABSORBED PRODRUG ESTERS}

John H. Bateson, George Burton*, Stephen C. M. Fell and Hazel C. Smulders

SmithKline Beecham Pharmaceuticals, Departments of Medicinal Chemistry and Microbiology, Brockham Park, Betchworth, Surrey, RH3 7AJ, U.K.

(Received for publication September 30, 1993)

In a previous communication ${ }^{1}$ we described analogues of cefotaxime (1) in which the C-3 acetoxymethyl group was replaced by a lactone (2). In our search for additional metabolically stable analogues, and encouraged by reports of some C-2 substituted penems ${ }^{2)}$, we targeted the $\mathrm{C}-3$ cyclic ether cephems $(3, n=1,2)$. Our synthesis adopted, in modified form, the Wittig cyclisation chemistry of WoODWARD et al. ${ }^{3)}$ and NAYLER et al.$^{4)}$ (Scheme 1).

The racemic acids (4) were converted in conventional fashion into the corresponding chloromethyl ketones (5), which were then used to alkylate the azetidinone thiol ${ }^{5)}(6)$. Addition of $t$-butyl glyoxylate to the derived ketone (7), followed by elaboration of the aminols (8) with thionyl chloride and 2,6-lutidine then tri- $n$-butylphosphine, provided the phosphoranes (9). On thermolysis in refluxing toluene these phosphoranes cleanly cyclised to the cephems (10) in high yields. As reported for the lactonyl derivatives ${ }^{1)}$, the use of tri- $n$-butyl phosphoranes in place of the triphenyl analogues was advantageous, the latter requiring prolonged reaction times or increased temperatures (thermolysis in xylene) resulting in greatly reduced yields. In addition the incorporation of benzoic acid catalysis ${ }^{6)}$ in the thermolysis of the tri- $n$-butyl phosphoranes reduced the time required for the completion of the cyclisation.

Removal of the 7-phenoxyacetyl group using standard cephalosporin methodology ${ }^{7}$ provided the 7-aminocephems. At this stage the $(R)-(11)$ and $(S)$-diastereoisomers (12) at position 2 of the ether ring were readily separated and independently acylated with 13 to give the diastereoisomers (14a and 14b). However subsequent removal of the $N$-trityl and $t$-butyl protecting groups from each of these with hydrochloric acid in formic acid, followed by formation of the sodium salts (3) was accompanied by epimerisation of the cyclic ether asymmetric centre. The same 2:3 mixture of $(R)-(S)$ was obtained from both enantiomerically pure intermediates (14a and $\mathbf{1 4 b})$. The sodium salts were alkylated with iodomethyl pivalate to provide the pivaloyloxymethyl prodrug esters (15) for oral absorption studies.

The antibacterial activities of the sodium salts (3) (Table 1) show that the tetrahydrofuran $(3, n=1)$ was significantly more potent than the tetrahydropyranyl analogue $(3, n=2)$ against several strains, and although it did not match the C-3 lactonyl analogues ${ }^{1)}$, compared favourably with cefuroxime, and cefetamet.

The oral absorption of the pivaloyloxymethyl prodrug esters (15) was examined in mice and compared with the $\alpha$-acetoxyethyl ester of cefuroxime (cefuroxime axetil ${ }^{8)}$ ) and the pivaloyloxymethyl ester of cefetamet (cefetamet pivoxil ${ }^{9}$ ). The results (Table 2) dramatically demonstrate that the C-3 cyclic ether cephems give vastly superior AUCs, peak concentrations in blood $\left(\mathrm{C}_{\max }\right)$ and half lives when compared to the standard compounds.
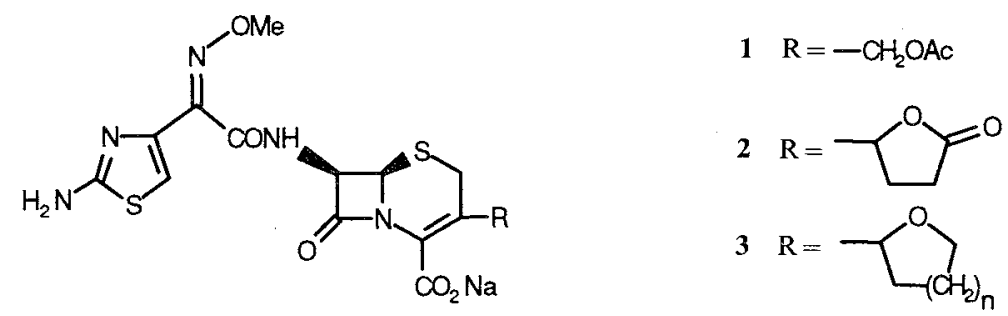

While this manuscript was in preparation, the preparation of a C-3 (3-bromotetrahydrofuran-2-yl)cephem was reported:

Jung, M. H.; K.-W. Cho, W. J. KIM, J.-S. ShIN \& C. S. PARK: Synthesis of cephalosporins having a heterocyclic group at the C-3 position. Bull. Korean Chem. Soc. 14: 32 34, 1993. 


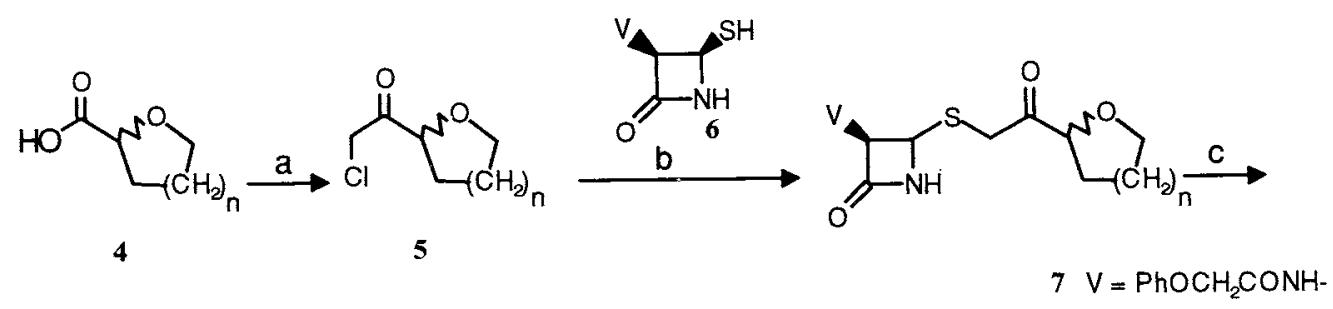

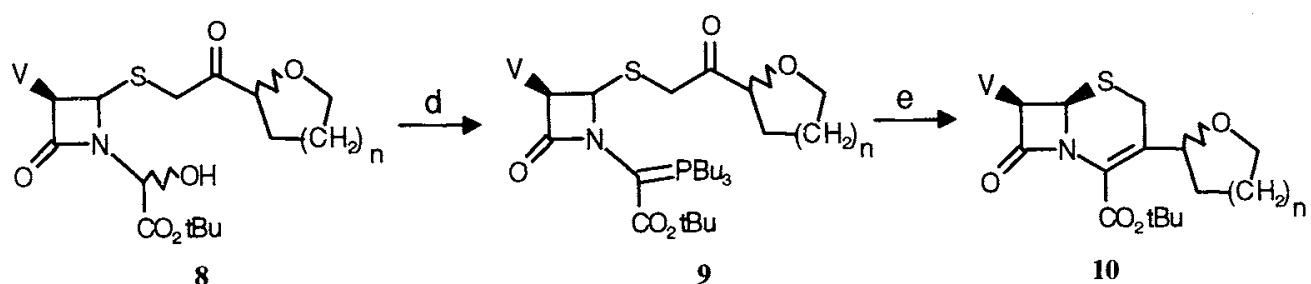

8

9

10

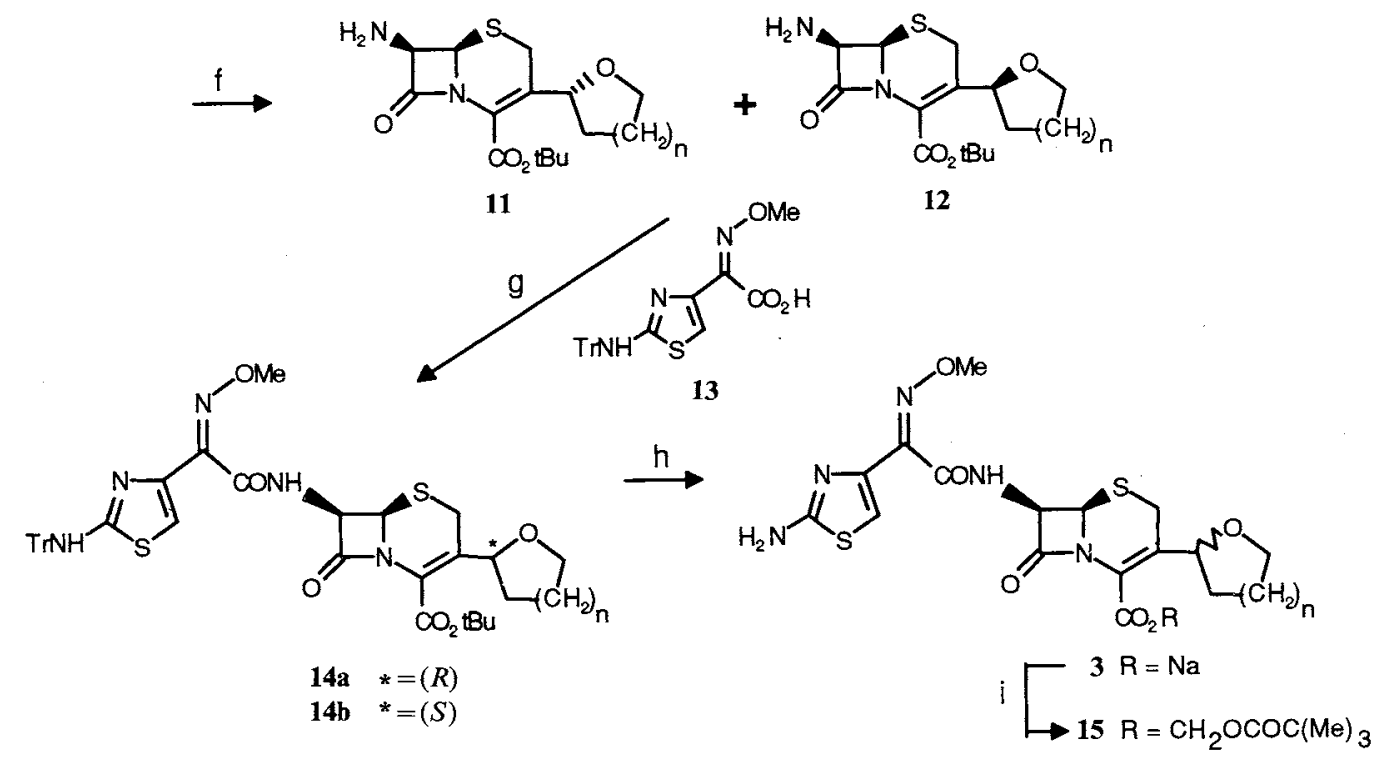

Reagents: (a) $\left(\mathrm{COCl}_{2}\right)$, DMF, $\mathrm{CH}_{2} \mathrm{Cl}_{2} ; \mathrm{CH}_{2} \mathrm{~N}_{2} ; \mathrm{HCl}$. (b) $\mathrm{K}_{2} \mathrm{CO}_{3}$, DMF. (c) $t$-Butyl glyoxylate, $\mathrm{NEt}_{3},\left(\mathrm{CH}_{2} \mathrm{Cl}\right)_{2}$. (d) $\mathrm{SOCl}_{2}, 2$,6-lutidine, THF; $\mathrm{PBu}_{3}$, dioxan. (e) Reflux, $\mathrm{PhMe}, \mathrm{PhCO}_{2} \mathrm{H}$. (f) $\mathrm{PCl}_{5}$, $N$-methylmorpholine, $\mathrm{CH}_{2} \mathrm{Cl}_{2} ; \mathrm{MeOH} ; \mathrm{H}_{2} \mathrm{O}$. (g) (13), $\mathrm{MeSO}_{2} \mathrm{Cl}, i \mathrm{Pr}_{2} \mathrm{NEt}$, DMF; (11) or (12), pyridine. (h) $\mathrm{HCl}, \mathrm{HCO}_{2} \mathrm{H} ; \mathrm{NaHCO}_{3}$. (i) $t-\mathrm{BuCO}_{2} \mathrm{CH}_{2} \mathrm{I}, \mathrm{DMF}$. 
Table 1. Antibacterial activity $\mathrm{MIC}\left(\mu \mathrm{g} \cdot \mathrm{ml}^{-1}\right)^{\mathrm{a}}$ of $\mathrm{C}-3$ cyclicether cephems.

\begin{tabular}{|c|c|c|c|c|}
\hline & $3(n=1)$ & $3(n=2)$ & Cefuroxime & Cefetamet \\
\hline Escherichia coli 10418 & 0.5 & 2 & 0.25 & 0.12 \\
\hline E. coli $\mathrm{ESS}$ & $<0.03$ & 0.06 & $<0.03$ & 0.12 \\
\hline$E$, coli $1077^{\mathbf{b}}$ & 1 & 8 & 2 & 0.25 \\
\hline E. coli $\mathrm{JT} 425^{\mathrm{b}}$ & 8 & 32 & 8 & 16 \\
\hline Haemophilus influenzae $\mathrm{Q} 1$ & 0.25 & 0.5 & 0.25 & 0.25 \\
\hline H. influenzae $\mathrm{NEMC1}^{\mathrm{b}}$ & 0.12 & 0.25 & 0.25 & 0.06 \\
\hline Klebsiella pneumoniae T767 & 1 & 8 & 2 & 0.25 \\
\hline Moraxella catarrhalis Ravasio ${ }^{b}$ & 0.5 & 4 & 2 & 1 \\
\hline Morganella morganii $\mathrm{T} 361$ & 0.5 & 4 & 32 & 2 \\
\hline Proteus mirabilis C977 & 0.5 & 4 & 2 & 0.12 \\
\hline Pseudomonas aeruginosa 10662 & $>64$ & $>64$ & $>64$ & $>64$ \\
\hline Enterobacter faecalis I & $>64$ & $>64$ & $>64$ & $>64$ \\
\hline Staphylococcus aureus Oxford & 1 & 1 & 0.5 & 64 \\
\hline S. aureus Russell ${ }^{\mathbf{b}}$ & 1 & 1 & 0.5 & $>64$ \\
\hline S. aureus $\mathrm{MB} 9^{\mathrm{b}}$ & 1 & 2 & 2 & 64 \\
\hline S. epidermidis PHLN 20 & 0.5 & 0.5 & 0.5 & 16 \\
\hline Streptococcus agalactiae 2798 & 0.06 & 0.06 & $<0.03$ & 2 \\
\hline S. pneumoniae 1761 & $<0.03$ & $<0.03$ & $<0.03$ & 0.5 \\
\hline S. pneumoniae PU $7^{\mathrm{c}}$ & 1 & 1 & 1 & 2 \\
\hline S. pyogenes CN 10 & $<0.03$ & $<0.03$ & $<0.03$ & 0.12 \\
\hline
\end{tabular}

a Serial dilution in blood agar base (Oxoid) containing $5 \%$ lysed horse blood. Inoculated with $0.001 \mathrm{ml}$ of an overnight broth culture diluted as appropriate.

b $\beta$-Lactamase mediated resistance.

c Target site mediated resistance.

Table 2. In vivo data ${ }^{\mathrm{a}}$ in the mouse of $\mathrm{C}-3$ cyclic ether cephem prodrugs.

\begin{tabular}{lcccc}
\hline & $\begin{array}{c}\text { AUC }(0 \sim 2 \text { hours }) \\
\left(\mu \mathrm{g} \cdot \mathrm{min} \cdot \mathrm{ml}^{-1}\right)\end{array}$ & $\begin{array}{c}\mathrm{C}_{\max } \\
\left(\mu \mathrm{g} \cdot \mathrm{ml}^{-1}\right)\end{array}$ & $\begin{array}{c}\mathrm{T}_{1 / 2} \\
(\text { hour })\end{array}$ & $\begin{array}{c}\text { Bioavail. } \\
(\%)\end{array}$ \\
\hline $\mathbf{1 5}(n=1)$ & 4201 & 47.3 & 1.77 & $58 \%$ \\
& {$[4264]^{\mathrm{c}}$} & {$[48.8]$} & & {$[52 \%]$} \\
$\mathbf{1 5}(n=2)$ & 4611 & 52.5 & 2.0 & $59 \%$ \\
Cefuroxime axetil & 437 & 8.6 & 0.3 & \\
Cefetamet pivoxil & 1216 & 23.3 & 0.46 & \\
\hline
\end{tabular}

a Following oral administration of esters (15) at a dose equivalent to $50 \mathrm{mg} \cdot \mathrm{kg}^{-1}$ of antibiotic (3).

b Bioavailability (\%) $=\frac{\text { AUC of prodrug ester (po) }}{\text { AUC of parent cephem (sc) }} \times 100$.

- [HPLC results] Concentrations of antibiotic in. blood measured by bioassay and confirmed by $\operatorname{HPLC}$ for $(3, n=1)$.

7-[2-(2-Aminothiazol-4-yl)-2-(Z)-2-methoxyiminoacetamido]-3-[tetrahydrofuran-2-yl]cephem $(3, n=1)$ has been identified as an analogue of cefotaxime which is well absorbed in the mouse as its pivaloyloxymethyl prodrug ester $(\mathbf{1 5}, n=1)$ and gives high and prolonged levels of antibiotic in the blood and is worthy of further studies.

Acknowledgments

The authors wish to thank Mr. P. CHEDD for synthetic assistance, Dr. D. J. Merrikin for the biological evalua- tion, and Mrs. S. J. KnotT and Dr. M. J. PEARson for discussions during the preparation of this manuscript.

\section{References}

1) Bateson, J. H.; G. Burton \& S. C. M. Fell: Synthesis and antibacterial activity of some C-3 lactonyl substituted cephalosporins. Bioorganic and Med. Chem. Letters 3: 2219 2224 1993

2) Ishiguro, M.; H. Iwata, T. Nakatsuka, R. TANaKa, Y. MAEda, T. Nishihara, T. Noguchi \& T. Nishino: Studies on penem antibiotics. I. Synthesis and in vitro activity of novel 2-chiral substituted penems. J. 
Antibiotics 41: 1685 1693, 1988

3) Scartazzini, R.; H. Peter, H. Bickel, K. Heusler $\&$ R. B. WoOdward: Neue $\beta$-Lactam-Antibiotika. Uber die Darstellung der '7-Aminocephalocillansäure'. Helv. Chim. Acta 55: 408 417, 1972

4) Nayler, J. H. C; N. F. Osborne, M. J. Pearson \& R. Southgate: Syntheses based on 1,2-secopenicillins. Part III. Hydration of 4-(3-substituted prop-2-ynylthio)azetidin-2-ones and a new cephalosporin synthesis. J. Chem. Soc. Perkin Trans. I 1976: $1615 \sim 1620,1976$

5) OsBorne, N. F.: The Chemistry of 4-mercaptoazetidin-2-ones. Part 1. Preparation and properties of (3R,4R)-4-mercapto-3-phenoxyacetamidoazetidin2-one. J. Chem. Soc. Perkin Trans. I 1980: 146 149, 1980

6) RÜChARDT, C.; S. EICHLER \& P. PANSE: Acid catalysis of a Wittig reaction. Angew. Chem. Int. Ed. 2: 619, 1963

7) Hatfield, L. D.; W. H. W. LunN, B. G. JACKSON, L. R. Peters, L. C. Blaszczak, J. W. Fisher, J. P. Gardner \& J. M. Dunigan: Application of phosphorus-halogen compounds in cleavage of the 7 -amide group of cephalosporins. In Recent Advances in the Chemistry of $\beta$-Lactam Antibiotics. Spec. Publ. No. 38, Ed., G. I. GreGory, pp. $109 \sim 124$, The Chemical Society, London, 1981

8) Ginsburg, C. M.; G. H. McCracken, Jr., M. Petruska \& K. Olson: Pharmacokinetics and bactericidal activity of cefuroxime axetil. Antimicrob. Agents Chemother. 28: 504 507, 1985

9) Peeters, M.\& P. P1ot: In vitro activity of Ro-15-8074, a new oral cephalosporin. J. Antimicrob. Chemother. 16: $469 \sim 473,1985$ 